\title{
Gold Ion Plating
}

\section{A RECENTLY DEVELOPED COATING PROCESS}

\section{E. W. Williams}

ICI Corporate Laboratory, Runcorn, England*

The availability of a new technique for the application of thin gold coatings to a variety of substrate materials must be of interest to a large number of gold users. Gold ion plating offers a number of technical advantages over more traditional gold coating processes and it us to be expected that it will compete with such processes to an increasing extent.

While electroplating was developed over a century and a half ago(1), ion plating, which was invented in 1963 by Mattox (2), is a very new process. It is therefore only very recently that industries involved in the application of surface coatings have begun to realise the full potential of this technique.

Interest in ion plating, especially outside the laboratory, remained at a low ebb until the First European Conference on Ion Plating and Allied Techniques (IPAT) was held in Edinburgh in June 1977 (3). Since that time, interest in Europe and North Amercia has been increasing at a rapid rate and products in the manufacture of which gold ion plating is now being used range from decorative coatings, through corrosion resistant films to optical filters.

\section{The Ion Plating Process}

Ion plating basically derives from the conventional evaporation and sputtering techniques and is best described in comparison with them.

Figure 1 is a schematic representation of the conventional evaporation (a), D.C. sputtering (b) and ion plating (c) processes. Conventional evaporation is used for the deposition of thin films of gold onto metallic substrates and provided the coat is less than $1 \mu \mathrm{m}$ in thickness, a degree of adhesion of the gold film to the substrate is achieved. However, for conventionally evaporated gold coatings on a wide range of non-metallic substrates, such as glass, plastics and ceramics, adhesion is very poor and the popular 'sticky tape test' usually completely removes the coating. The vacuum required for the evaporation of most

*The author is now with EMI, Central Research Laboratories. Hayes, England

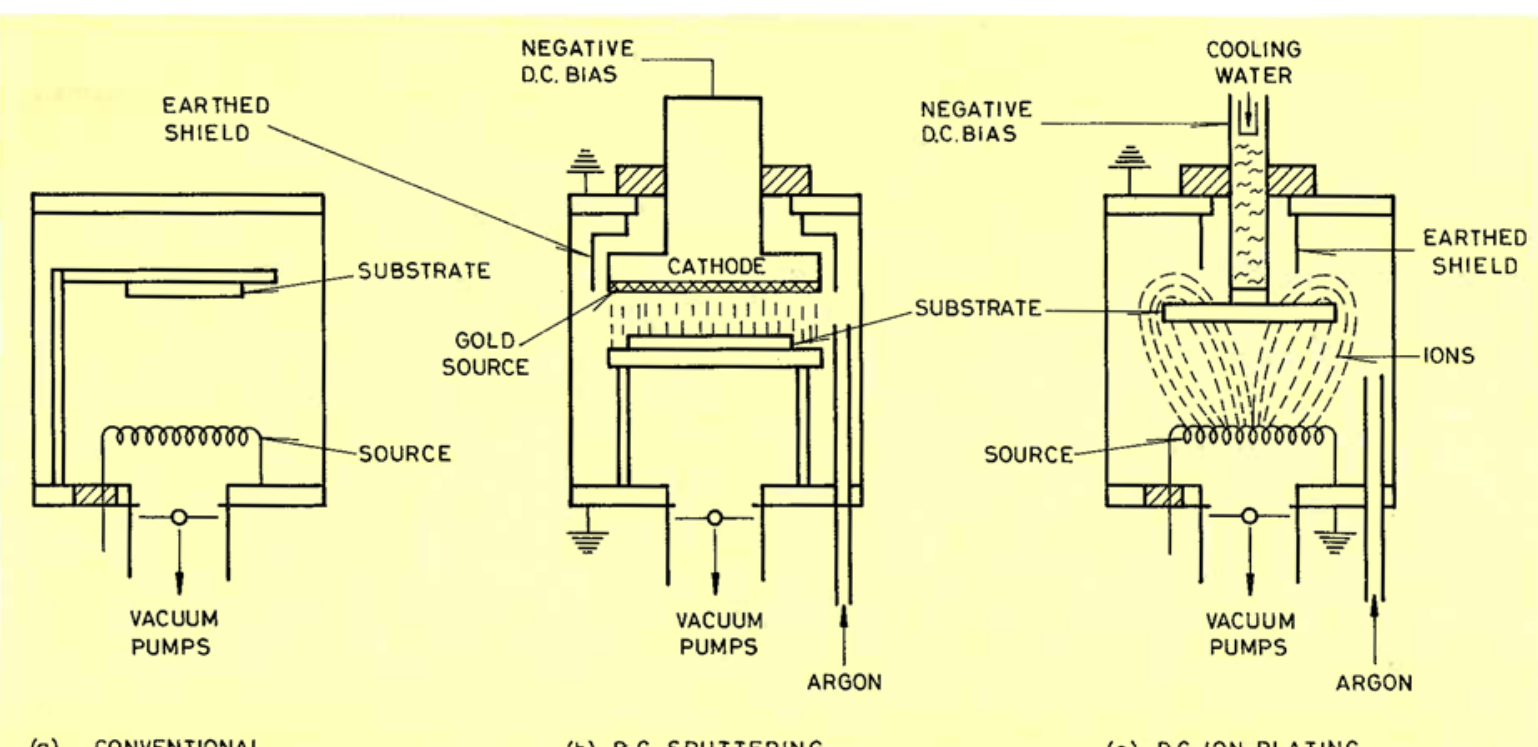

(a) CONVENTIONAL

(b) D.C. SPUTTERING

(c) D.C. ION PLATING

Fig. 1 Schematic comparison of three related gold deposition processes: (a) conventional evaporation (b) D.C. sputtering (c) D.C. ion plating 
metals must be $0.001 \mathrm{~Pa}$ or lower so pump down times are quite long with most of the small bench top units. In the case of gold, because it resists oxidation at high temperatures the evacuation conditions need not be so stringent and a pressure of $0.01 \mathrm{~Pa}$ is adquate. The gold wire or foil is melted in the low voltage tungsten filament basket source until the gold wets the source wire. During this melting process a shutter, which is not shown in the diagram of Figure 1 (a), remains in place to prevent gold particles and impurities from reaching the target. Once melting is complete, the shutter is removed and the evaporation commences by raising further the temperature of the source. Evaporation ceases either when all the gold is used up or as the operator reduces the current through the source when a film thickness monitor indicates that the required coating thickness has been deposited.

Conventional evaporation equipment is relatively simple and for the same size of vacuum unit and bell jar is always cheaper than that for sputtering or ion plating. It is also has the advantage that the substrate on which the film is to be deposited can be suspended from a clamp fitted to the base of the unit, and does not require a vacuum 'feedthrough'. The smaller number of vacuum feedthroughs means that there are fewer places where leaks can occur.

Although sputtering and ion plating processes are normally more expensive, the coating adhesion obtained is much stronger than with conventional evaporation for the vast majority of coating and substrate material combinations. The main reason for this is that the energy of the incident metal atoms is higher. This is clearly shown in Figure 2 which indicates the metal atom or ion energy range in the three processes of Figure 1 and also that for ion implantation. For evaporation the energy ranges from 0.1 to $1 \mathrm{eV}$ compared to sputtering where it ranges up to $30 \mathrm{eV}$. With ion plating, on the other hand, it can go up to several thousand $\mathrm{eV}$.

Only a very brief outline of sputtering will be given and the reader is referred to Maissel and Glang (4) for a review of sputtering methods. Figure 1(b) shows a simple sputtering rig. The source or target in the form of a gold disc is fixed onto a cathode. The substrate is positioned just below the source on an earthed electrode. After evacuating the bell jar in the normal way to a pressure of about $0.001 \mathrm{~Pa}$, argon is admitted until the pressure reaches about $100 \mathrm{~Pa}$. A discharge is then produced by establishing a cathode voltage above 1000 volts. Positive argon ions in the plasma are accelerated towards the cathode and on striking the target they eject gold ions

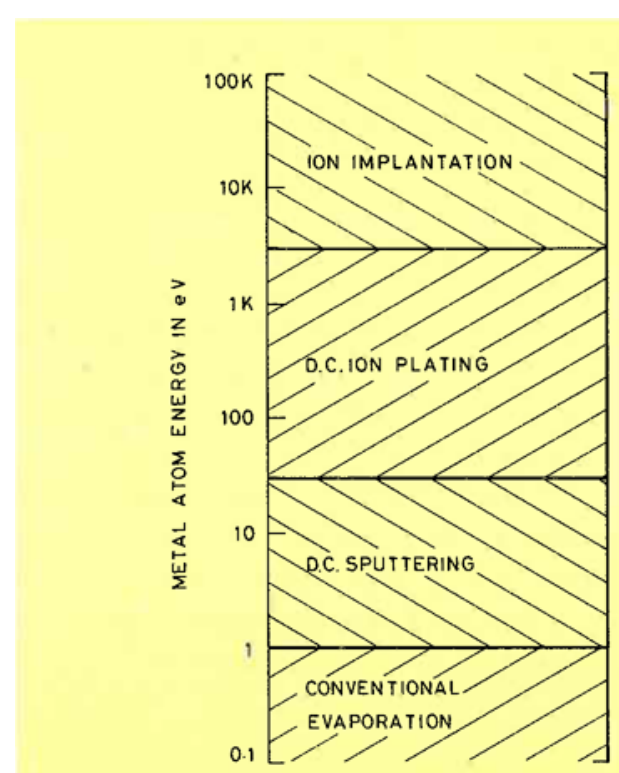

Fig. 2 Metal atom or ion energy ranges for evaporation, sputtering, ion plating and ion implantation. (Logarithmic scale)

and secondary electrons. These ions are then accelerated towards the earthed substrate and deposited onto it. Those of the secondary electrons that strike argon atoms cause ionization and maintain the plasma. Some of the electrons reach the substrate and raise its temperature to well over $100^{\circ} \mathrm{C}$. An earthed shield around the side of the cathode contains the plasma in front of the source.

D.C. ion plating has recently been reviewed by Teer (5). The process, as shown in Figure 1 (c) has some of the features of both conventional evaporation and sputtering. As in sputtering, argon is admitted to the jar until the pressure reaches about $100 \mathrm{~Pa}$ and a discharge is struck between the earthed source and the substrate cathode. The argon ion plasma is firstly used to sputter-clean the metal substrate onto which the gold is to be deposited. The time required for the cleaning will depend on the metal but for steel about 30 minutes is required. After cleaning, gold is evaporated in the manner described above and enters the plasma. Gold atoms and ions are scattered by the argon ions and are accelerated towards the substrate where they deposit. As a result, excellent bonding is achieved between the deposited gold and the substrate. Film adhesion is also enhanced by the sputter cleaning which goes on during the deposition and removes any material loosely bonded to the substrate; it is also increased by diffusion in cases in which alloys can form between the gold and the substrate. The diffusion takes place more rapidly if there is no water cooling of the cathode since 
temperatures in excess of $400^{\circ} \mathrm{C}$ are produced by the ion bombardment. With the earthed shield designed to protect only the top part of the cathode, as the diagram shows, the plasma extends to the back of the substrate so that gold plating occurs on the back as well as the front. With the substrate stationary the gold film is only half as thick on the back as on the front, but by rotating the sample in the plasma a uniform thickness is obtained. Some gold ion plated samples are shown in the photograph in Figure 3.

Gold ion plating onto metals like steel, copper and aluminium gives excellent film adhesion in every case but in the case of non-conductors like plastics and ceramics problems occur because of the D.C. biasing or charge accumulation. Careful cleaning and treatment before the plating is necessary for most non-conductors and handling after cleaning must be done with appropriate precautions. The use of a conductive mesh cage in front of the non-conductive substrate has enabled reasonably good adhesion to be obtained with gold on plastics like Polyethersulphone while 'lightning' discharge and burning out of the surface coating have been avoided. Jones etal. have described in some detail the use of D.C. ion plating for plastics $(5,6)$.

It is likely that in the near future radiofrequency (R.F.) biased ion plating will replace D.C. biasing for coating of plastics and other non-conductive substrates and some preliminary work in this area has recently been reported (7).
It is obvious that ion plating is a higher energy process than sputtering when the two techniques are compared as in Figure 1. In the case of sputtering the process is a secondary one in that the target atoms have first to be sputtered off the source and then only deposit onto the earthed substrate. With ion plating the process is a direct one as thermal energy is supplied for the evaporation of the gold.

The energy of the metal atoms which deposit onto the substrate depends on the magnitude of the bias. In contrast to ion implantation, in ion plating the impact energy can be made sufficiently low so that crystalline substrates like silicon can be plated without damage. Consequently, the area of electronic device fabrication is beginning to open up for ion plating. There is little doubt that gold and gold-alloy ion plating will have an important part to play in the electronics business of the future.

\section{The Advantages of Gold Ion Plating}

In spite of being a new technique, with development work still in progress, there appear to be a number of advantages attached to gold ion plating. Some of these advantages arise from the exceptional properties of gold, whereas others arise from the nature of the ion plating process.

\section{Economic Advantages}

Because of the unreactive nature of gold, the vacuum conditions in the equipment used for ion

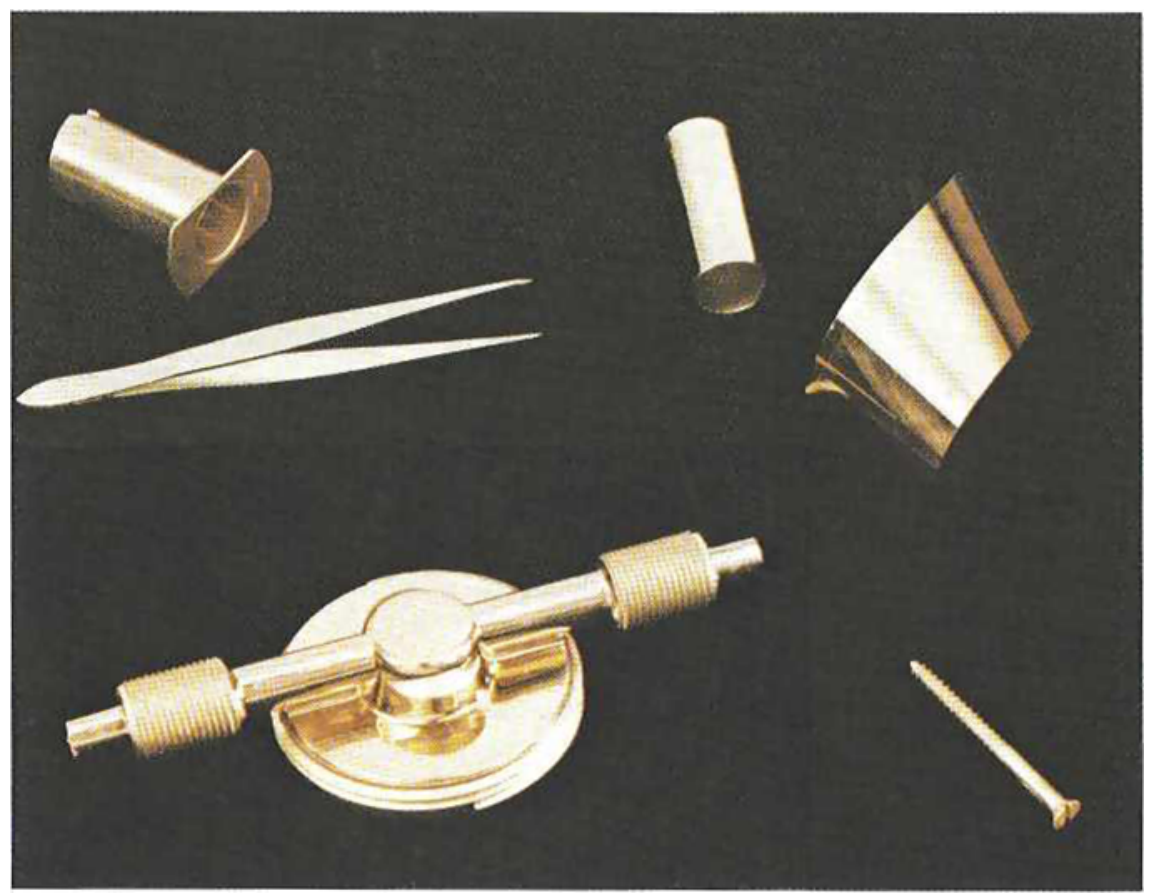

Fig. 3 The versatility of ion plating is illustrated by examples of components of various shapes and materials which were gold coated by the process. Clockwise, the objects in this photograph are: a piece of stainless steel tubing, a piece of polyimide plastic foil, a steel screw, a valve moulding of Polyethersulphone (an ICI plastic), a pair of stainless steel tweezers and a part of a polypropylene syringe. The gold coatings on all these objects are in the range 2000 to $5000 \AA$ thick 
plating are not critical. This means that simple vacuum units, which are inexpensive to operate and maintain can be used. For instance, a small bench top unit is quite suitable for the coating. of small jewellery items. Further, the required moderate vacuum is normally achieved after very short pumping times. This, together with the fact that gold plated samples can be withdrawn from the unit when they are still hot without any damage or detrimental oxidation, results in rapid rates of batch processing. It can be anticipated that when high rates of evaporation can be applied without any loss of adhesion, batch processing times will be a few minutes only.

Another consequence of the non-critical vacuum conditions required for gold ion plating is that its application to continuous plating of metal foil or plastic strip is simplified. With conventional evaporation, reel to reel coating inside the chamber or alternatively travel through four vacuum-to-air seals is mandatory to maintain a high vacuum inside the chamber. With ion plating, a single seal is sufficient and there is no limitation to the size of the rolls of substrate as these are located outside the coating unit.

Small ion plating units are simple and operators can be trained in a matter of hours. However, powerful units for high rate deposition, which use an electron beam or a magnetron sputter source, are more complicated and operator training time is longer.

The power consumption of the process is low, in part because the melting point of gold $\left(1064^{\circ} \mathrm{C}\right)$ makes for easy evaporation. Much smaller amounts of gold are used with ion plating than with conventional evaporation to achieve the same coating thickness. This results from the concentrating effect of the plasma which directs the gold onto the cathodic specimen. A shield with a small viewing port can be used inside the bell jar to collect most of the gold that does not go into the plasma. This gold can periodically be recovered by peeling it off the shield.

Lastly, the process is entirely pollution-free which has a beneficial effect on both investment and operating costs.

\section{Properties of the Coatings}

As recorded earlier, one of the main features of gold coatings deposited by ion plating is their excellent adhesion to a variety of materials. This is normally achieved without particular difficulty on all metallic substrates and on ceramics with a rough surface finish. If reasonable adhesion to polished ceramics or high surface quality plastics is to be obtained, then careful cleaning is essential prior to coating.
Provided that the right operating conditions are used, films of high electrical conductivity are produced. High surface reflectivity is also one of the advantages exhibited by ion plated deposits, which have proven suitable for optical applications. The surface finish obtained is certainly better than that achieved by conventional electroplating on an identical substrate.

Substantially pinhole-free gold deposits can be prepared by ion plating. This is important when coatings are to provide corrosion protection and is achieved by thinner coatings than with electroplating.

\section{Area of Application}

The possibility of coating non-conducting materials by gold ion plating opens up a wide range of applications for the process. In addition to the virtually unrestricted choice of substrates, the high throwing power inherent in ion plating means that almost any shape can be coated. For example, a tube can be coated internally in one run provided that its length is not more than four times the diameter. For longer tubes or complex shapes, special electrodes and/or sample rotation can be used.

Also, due to the excellent adhesion of the coatings, ion plated components are particularly suited for applications which involve subsequent bonding or demanding electrical properties.

Gold alloys and some compounds can be deposited by ion plating. However, compositional control is poor with the standard filament evaporation or with an electron beam source. Improved control should be achieved with a sputter source.

\section{Conclusion: Electroplating or Gold Ion Plating?}

A comparison between ion plating and electroplating has been tabulated (8). The main advantages of ion plating over electroplating are that it is a pollution-free process which gives highly adherent gold coatings on a wide range of conducting and non-conducting substrates and the films have high optical, electrical and non-porous qualities even when they are less than $1 \mu \mathrm{m}$ in thickness.

Electroplating is a cheaper process and generally is much simpler to operate. However, in the author's opinion, the advantages of gold ion plating and the new applications it is opening up in the field of electronics and optical communications, optical instruments, decorative and corrosion protection coatings, leave little doubt that it will become increasingly competitive with electroplating in many areas. 
Table

A Comparison of the Electroplating and Ion Plating Processes

\begin{tabular}{|c|c|c|c|}
\hline A & Features of the process & Electroplating & Ion plating \\
\hline & Materials that can be deposited & Pure metals, alloys & $\begin{array}{l}\text { Pure metals, alloys, some } \\
\text { inorganic compounds }\end{array}$ \\
\hline & Non-conducting substrates & $\begin{array}{l}\text { Not possible without } \\
\text { autocatalytic preplating }\end{array}$ & Yes - a wide range \\
\hline & Deposition rate $(\AA /$ second $)$ & 0 to $10^{4}$ & 10 to $10^{3}$ \\
\hline & Throwing power & Limited & Good \\
\hline & Substrate temperature & 20 to $100{ }^{\circ} \mathrm{C}$ & $\begin{array}{l}50 \text { to } 400{ }^{\circ} \mathrm{C} \text { depending on } \\
\text { power levels and cathode cooling }\end{array}$ \\
\hline & Cost & Moderate & High \\
\hline & Simplicity of equipment & Simple in most instances & $\begin{array}{l}\text { Simple only for small batch } \\
\text { processing }\end{array}$ \\
\hline & Gold recovery & Costly & Relatively simple \\
\hline & Pollution & $\begin{array}{l}\text { Problems - especially with } \\
\text { cyanide }\end{array}$ & None \\
\hline B & Properties of the deposits & Electroplated & Ion plated \\
\hline & Adhesion & Moderate & Excellent \\
\hline & Porosity & Usually porous for thin coatings & $\begin{array}{l}\text { Generally non-porous if care is } \\
\text { taken }\end{array}$ \\
\hline & Uniformity & $\begin{array}{l}\text { Good on flats but may have } \\
\text { non-uniformity on edges }\end{array}$ & $\begin{array}{l}\text { Good on the front surface but } \\
\text { will be thinner on the back. } \\
\text { Rotation ensures uniformity }\end{array}$ \\
\hline & Purity & $\begin{array}{l}\text { May contain gases and } \\
\text { inclusions of inorganic or } \\
\text { organic nature }\end{array}$ & $\begin{array}{l}\text { Limited only by purity of the } \\
\text { source material }\end{array}$ \\
\hline & $\begin{array}{l}\text { Resistance to tarnish and } \\
\text { corrosion }\end{array}$ & Excellent & Excellent \\
\hline & Electrical conductivity & $\begin{array}{l}\text { Good for thick layers } \\
\text { Moderate for thin layers }\end{array}$ & Good \\
\hline & Optical reflectivity & Good & Excellent \\
\hline
\end{tabular}

\section{Acknowledgements}

The author is grateful to D. G. Teer for many helpful discussions on ion plating and to Professor Takagi for the information in Figure 2. Keith Jones provided invaluable experimental assistance and produced all the samples shown in Figure 3.

\section{References}

1 L. B. Hunt, Gold Bull., 1973, 6, 16-27

2 D. M. Mattox, J. Appl. Phys., 1963, 34, 2493

3 'Proceedings of the IPAT 77 Conference', available from CEP Consultants Ltd., 14a Henderson Row, Edinburgh EH3 $5 \mathrm{DH}$
4 'Handbook of Thin Film Technology', ed. by L. I. Maissel and R. Glang, McGraw-Hill. 1970

5 D. G. Teer, in 'Proceedings of the IPAT 77 Conference', 1977,13

$6 \mathrm{~K}$.Jones, A. J. Griffiths and E. W. Williams, in 'Proceedings of the IPAT 77 Conference', 1977, 115

7 E. W. Williams, K. Jones, J. M. Bell and D. G. Teer, in 'Proceedings of the Advances in Surface Coating Technology Conference', The Welding Institute, London, February 1978

$8 \mathrm{~A}$ few of the comparisons shown in this table are taken

from: R. I. Sims, Metal. Mater. Technol., 1976, 8, (1), 23-27 N. J. Archer and L. C. Archibald, Chart. Mech. Eng., 1977, 24, (2), 59-63 